\title{
Instructor Perceptions in the Assessment of Student Digital Voice Reflections
}

\author{
Dana A. Tindall, The Christ College of Nursing and Health Services, Cincinatti, Ohio \\ Kay K. Seo, University of Cincinnati
}

\begin{abstract}
The ubiquitous presence of technology with multimedia capabilities provides ample opportunity for innovative pedagogical strategies. Digital voice reflection is born out of a need for expediency, convenience, and multimodal forms of learning. It allows students to quickly capture reflective thought through the naturalness and primacy of the spoken word. It also allows an instructor to more easily examine the reflective thought process presented through voice inflection, manner of speaking, and relative conciseness of thought. To explore what elements or factors unique to vocally expressed and recorded reflection instructors notice and consider important for assessment, this study surveyed 60 instructors from 14 Midwestern universities and colleges of nursing and identified 15 unique factors falling within four broader categories to be used for assessment of voice reflections.
\end{abstract}

Keywords: reflection, voice reflection, assessment

\section{Introduction}

Reflection is an important part of higher education and is often used in the curriculum as a formational tool for teaching subject matter and for the development of professionalism.

Reflection is a personal, sometimes emotion-laden return to earlier experience; it is a narrative created internally through a process of expectation, active exploration, and critical resolution, which can then be held and used to influence action in future situations. It is creation of personal knowledge, an ongoing process in which critical thought processes influence and transform the individual (Meizirow, 1981; Schön, 1991). Becoming critically reflective is a key to transformation of frames of reference that are indispensable in the process of adapting to change (Mizerow, 1997). Reflective practice, specifically Schön's (1991) term "reflectionon-action," is central to professional practice, and refers to personal consideration of an experience after it has occurred.

Over time, the technology for the creation and sharing of reflective activity as part of pedagogical strategy has transformed and is continuing to change. Technology now permeates the world of higher education. Use of computers by students and instructors as tools for teaching and learning is ubiquitous and is shifting to include the use of mobile devices such as tablet computers and smart phones out of a student-perceived need for convenience. Young people are often skilled multi-tasking users of technology, and most rely on it for information gathering and communication (Bennett, Maton, \& Kervin, 2008). A 2013 ECAR study of undergraduate students and information technology finds that "students are ready to use their mobile devices more for academics, and they look to institutions and instructors for opportunities and encouragement to do so" (Dahlstrom, Clark, \& Dzuiban, 2013, p. 4). It is important that a primary teaching and learning tool such as reflection be adapted to fit technological changes and better serve the student and the instructor.

Digital voice recording applications are common to both regular computers and smaller mobile devices, and they are convenient and easy to use. Technological progress in educational settings, as well as students' desire to use convenient technologies, makes recording speech for reflection worthy of study. However it is important to consider that recorded reflections will include unique elements not seen in text-based ones. Thoughts that were once written in text will be replaced by the sound of the student's voice, and vocal elements such as in- 
flection and the vocal manner of presentation will essentially replace text-based components such as punctuation, paragraph, and sentence structure. Therefore, instructor perceptions and strategies for assessing them will be somewhat different as well.

This study investigated what unique elements of voice reflections instructors noticed and what factors they found important for assessing those reflections. We focused on nursing instructors' perceptions here. Courses in nursing often include reflection as a key element, adding it to the course curricula by integrating it into activities, and using students' reflection-on- practice material as a part of a formal assessment strategy (Hannigan, 2001). Students in nursing are involved with active participation in simulation labs and also in clinical learning environments where they work as apprentice staff alongside supervising nurse instructors in a variety of healthcare settings. Assessment of those student activities comes through face-to-face debriefings with the instructor, as well as writing assignments such as reflections where the student is prompted to consider the experience, write meaningfully about it, and share it with the instructor. The time spent by students writing reflections can be lengthy and can occur relatively long after the experience, possibly leading to details being lost. The convenience of voice recording can make the process more expedient.

\section{Reflection and Assessment}

Reflective capacity is essential for professional competence. Integration of theory and practice by way of repeated reflective practice is an integral part of learning for students in the health professions (Hannigan, 2001; Mann, Jordon \& MacLeod, 2009; Smith, 2011). It is assumed that reflection is positive, contributes to development, and increases the quality of practice (Asselin, Schwartz-Barcott, \& Osterman, 2012), and without question it is a valuable part of the professional educational experience particularly for students of nursing.

Nursing students are assigned to reflect on many aspects of their educational experiences, which include classes, case studies, and mechanical patient simulations, as well as clinical experiences with real patients. Such considerable activities produce much scholarly writing and research. While all these writings closely circle the construct of reflection they appear to differ in their approach. Mann, Jordan, and MacLeod (2009) provided a comprehensive literature review of reflection used in health professions education and found the models of reflection to basically follow two general dimensions. They define one as being an "iterative dimension," where the process is caused by experience that creates new understanding and the reasoning to act differently in the future, as advocated by Boud, Keogh, and Walker (1985) and Schön (1991).

The other is a "vertical dimension," which considers a hierarchical level of reflection on experience from one of being simply descriptive to critical, as supported by Dewey (1910/2001), Hatton and Smith (1995), Kember, McKay, Sinclair, and Wong (2008), Mezirow (1991), and Moon (1999). These means of defining reflection provide the opportunity and criteria for developing some sort of assessment. Moreover, as nursing curricu- la frequently depends upon reflection as a necessary component, an educator must decide how to apply that assessment in a meaningful way to spur learning, but at the same time not inhibit students' learning processes.

The assessment of reflection, however, can be a difficult task. Osborne and Walker (2013) state that current assessment models demand that the instructor translate his/her expertise into a set of rigid rules, but they go on to say "a rubric cannot begin to encompass everything a rater knows and utilizes when evaluating" (p. 40). They find that the practice of assessment should instead rely on a more fluid application in the use of an instructor's own expertise that is effective and meaningful. Assessment of reflection can be formative or summative in nature.

The instructor must consider whether the reflection's purpose is formative as a short, informal and personal collection of thoughts, or instead a summative formal professional reflective response. The notion of what is actually being assessed is additionally important: is it the student's demonstration of ability to reflect skillfully, or is it instead the student's response to learning and experience that is being assessed.

In many cases, assessment depends upon creation of a criteria framework built into the map of the curricular course design (Moon, 2004). Reflective prompts will be needed "to focus learning, motivate students to learn, shape or direct learning, and to require that student can apply or transfer their learning to unexpected situations" (p.150). Assessment may also be based upon depth as perceived by the instructor. Kember, McKay, Sinclair, and Wong (2008) developed and tested four hierarchical levels of assessment for measuring student reflection, ranging from "habitual action" to the "critical reflection" as defined by Meizirow (1981). The lowest level, "habitual action," is a simple regurgitation of fact, which is not considered reflection and does not necessarily involve or associate with any sense of meaning. The next higher level, "understanding," does not imply reflection; it is understanding of concepts or theories but does not make the connection to practice, practical situations, or personal experiences. The next level, "reflection," considers the application of a concept to personal functions. Personal insight becomes apparent at this level and experiential situations are related to what has been taught.

The highest level is "critical reflection," where personal deep-seated and embedded presuppositions are reassessed and reconstructed internally in the light of new experience or learning.

As described above, the assessment of reflection is not a simple task. It is important for instructors to read reflections not only for evidence of content but also for the experiential meaning. Pierson (1998) suggests that reflection is both a technique and a process related to the German philosopher Heidegger's notions of calculative thinking, that being an "abstract and practical process confined to organizing, managing and controlling," and the concept of contemplative thinking, that being "a natural and spontaneous process fundamental to the exploration of meaning" (p. 166). Reflection then as "technique and process" becomes a learned skill. Educators must find ways of providing the valuable time 
and means to reflect "in action" and "on action." In this regard, exploration into which unique vocal elements instructors consider when assessing a student's voice reflection is important. The understanding of what elements are noticed and which of these are important can assist an instructor in formation of a reflective prompting structure for the student, and can additionally help form an assessment strategy for these types of reflective assignments.

\section{Instructor Perceptions on Digital Voice Reflections, Methods, and Results}

To explore instructors' perceptions in the assessment of student digital voice reflections, we conducted a cross-sectional survey, which is usually used to collect data from a pre- determined group at a single point in time to help describe characteristic opinions and attitudes of a specific population (Fraenkel \& Wallen, 2009). This survey design type was considered appropriate because the use of voice reflections in nurse education is a new application of technology, and perceived factors unique to voice reflections that nursing instructors can use for assessment has not been fully determined. The study was designed to be done in two consecutive phases. In the first phase we surveyed a sample of instructors from a small college of nursing, and in the second phase we surveyed a larger sample of instructors from several colleges of nursing. The aim of the first phase of the study was to identify a list of perceived unique factors or elements found in a voice reflection. The second larger phase of the study was designed to validate and refine the list of factors created in the first phase and then to ask instructors to rate the factors for importance to assessment.

\section{Phase One}

For the first phase, we recruited nine consenting instructors, eight female and one male, for a face-toface survey session. The selection of recruited instructors was chosen because they teach both didactic and clinical classes, and are experienced nurses and instructors. This group's average number of years in nursing was 22.7 years, and years teaching was 9.4 years. These instructors had no previous exposure to voice reflections, so they had no pre-conceived notions or bias toward any factor or elements found there. This is important because they could begin by identifying what factors they might expect to be present. The instructors were asked to conduct three tasks. First, they were asked to list factors/elements they expect to notice when listing to the student's voice reflection; no minimum or maximum number of factors was required. After the instructors completed the first step, we played two random selections from a group of five voice reflections (ranging from 1 minute 57 seconds to 3 minutes 28 seconds) generated by nursing students after completing their required clinical experiences. Immediately after listening to the two reflections, they were asked to numerically rate the items from one (low) to five (high) for usefulness in assessment; they were allowed to add any others they noticed or felt important.

We found that many of the factors/elements listed by the instructors were very similar in terms of intent, theme, and ratings. Each respondent listed between 2 and 8 factors $(M=4.4)$.
Factors provided ranged from a single word to several word descriptions, (e.g., "overall learning experience/what the student will carry forward"). All those factors that had been rated three or more were developed into a list and similar items were combined based on theme. We then divided that list into four themed factor categories: a) care and meaningfulness, b) the student's orientation to tasks and learning, c) the student's manner of speaking, and d) the recording quality and the tone of the student's voice (inflection). Each category contained a number of discrete sub-factors ranging from two for "care and meaningfulness" to six for "student's orientation to tasks and learning" (see Table 1).

\section{Phase Two}

The second phase of the study used a larger online sample of nursing instructors. We surveyed 60 respondents, 53 female and 7 male, from 14 Midwestern universities and colleges of nursing. The study was taken to an online format where the sample respondent population could be easily targeted and recruited. The consenting respondents were first informed of the steps to complete the survey. The respondents were then shown a page with a survey-generated random order list of the five voice reflections. They were instructed to select only one reflection and then click on a "play" arrow next to it to listen. The respondents were prompted in the next step to check small boxes by the factors they noticed when listening. They were provided a textbox option to add any other factors they noticed should they desire. The respondents then moved to the last step where they were asked to suppose they were assessing a voice reflection and rate the items on a 5-point Likert scale from one ("not important at all") to five ("very important") in terms of its significance in their assessment. They were also asked to list any factors not listed that they felt might be important for assessing a student's voice reflection.

We had decided earlier, based on feedback from the first phase of the study, that including the factor category of "care and meaningfulness" would appear redundant when scoring importance ratings for its two sub-factors, "caring attitude/empathy for patient" and "reflection on experience (personal meaningfulness)." Consequently it was not included in the list when the online survey was created.

To gain additional information about the respondents' opinions and the choices they made, we gave them the option to write additional comments. These comments provided valuable qualitative data to help corroborate the quantitative data the survey provided.

The data collected were analyzed using descriptive statistical methods to yield mean and median scores for the factor importance ratings found in the survey. The qualitative data were also examined using grounded theory techniques to find common respondent observations and themes.

We found that a small number of respondents did not rate some items, thus the mean score for each item does not necessarily represent opinions from the entire population. Two of the items received a rating from the entire sample population, and the lowest response rate 
for any item was 53. The mean rating value for each of the items shows that the top 14 factors out of the total list of 18 were rated above a value of four, which is considered "somewhat important." Ten of this group had a mean value at or above 4.5 , and 12 had a median value of five. The highest mean values were for "expression of what was learned/discovered" $(M=4.8$, $M d n=5, S D=.6)$, "evidence of critical thinking/ thought" $(M=4.8, M d n=5, S D=.5)$, "caring attitude/ empathy for patient," "the student's orientation to tasks and learning" (both $M=4.8, M d n=5, S D=.5$ ), and "reflection on experience (personal meaningfulness)" ( $M=4.7, M d n=5 . S D=.5)$.

The lowest rated items were "presenting a simple list of tasks performed" $(\mathrm{M}=3.4, \mathrm{Mdn}=3, \mathrm{SD}=1.1)$, "presence of background sounds/voices" $(\mathrm{M}=3.4, \mathrm{Mdn}$ $=3, \mathrm{SD}=1.2)$, and "informal tone in speaking" $(\mathrm{M}=$ 3.5, $\mathrm{Mdn}=4, \mathrm{SD}=1)$. (see Table 2).

When asked to list any other factors they noticed or felt were important for assessing a student's voicejournal, they mentioned "HIPPA compliance." HIPPA stands for the Health Insurance Portability and Accountability Act enacted in 1996, which demands compliance with strict privacy for individuals concerning health information. This is an important factor in healthcare, and great effort to stay in compliance is always expected in nurses and nursing students. Other comments did not necessarily focus on factors, mostly aimed toward the theme of student guidance. Examples are "training or an expectation of what the instructor expects might be helpful to provide before the students' record their reflection," and "provide a list of expectations for the reflection rather than letting them just ramble on without direction." The instructors also commented on elements that should be included in guid- ance, e.g., "the mention of patient response to treatment or care," and "I think it would be interesting to have the students discuss areas of improvement or what they might do differently in their next clinical assignment."

\section{Discussion and Implications}

The qualitative data suggest that instructors should prompt students to be cognizant of the tone of voice used when recording a voice reflection, and be precise and focused in their manner of speaking. They should always attempt to not sound bored, superficial, or uninterested in their presentation. The students should make attempts to sound professional, on topic, and comfortable using terms appropriate to the profession. This is appropriate as reflection contributes to a student nurse's development and quality of practice (Asselin, SchwartzBarcott, \& Osterman, 2012).

They should be organized and verbally concise in their presentation, and use an appropriate amount of recording time. To this end, time limits should be included in the voice reflection guidelines. Students should be instructed, or somehow guided to go beyond providing only a simple list of tasks performed in their reflections. They should attempt to critically tie information from their classes to the clinical experience in a reflective manner that focuses on personal and professional improvement. The reflection should have an "iterative dimension" where the experience creates a new understanding and way of going forward (Mann, Jordan, and MacLeod, 2009). Students should also take care to present an attitude showing care and empathy for the patients they report on.

Table 1

\section{Noticed Unique Factors}

\begin{tabular}{ll}
\hline Factor Category 1 & (C) Care and Meaningfulness \\
(C1) Caring attitude/empathy for the patient & (C2) Reflection on experience (personal meaningfulness) \\
\hline Factor Category 2 & (T) The student's orientation to tasks and learning \\
(T1) Presenting a simple list of tasks performed \\
(T2) Presenting evidence of task prioritization \\
(T3) Comfort with nursing topics and terms \\
(T4) Information connected between classroom/clinical experience \\
(T5) Evidence of critical thinking/thought \\
(T6) Expression of what was learned/discovered \\
\hline Factor Category 3 \\
(M) The student's manner of speaking \\
(M1) Professional manner of speaking \\
(M2) Informal tone in speaking \\
(M3) Organized manner of presentation \\
(R) The recording quality and the tone of the student's voice (inflection) \\
(R1) Enthusiastic tone \\
(R2) Bored or frustrated tone \\
(R3) Superficial or distracted tone \\
(R4) Presence of background sounds/voices
\end{tabular}


Table 2

Instructor Responses by Categories and Sub-Factor

\begin{tabular}{|c|c|c|c|c|}
\hline & $\begin{array}{c}A l l \\
M / S D\end{array}$ & $\begin{array}{c}\text { Female } \\
M / S D\end{array}$ & $\begin{array}{l}\text { Male } \\
\text { M/SD }\end{array}$ & $\begin{array}{c}\text { Total } \\
\text { responses }\end{array}$ \\
\hline (C) Care and Meaningfulness & -- & -- & $--4.4 / .8$ & -- \\
\hline (C1) Caring attitude/empathy for the patient & $4.8 / .5$ & $4.8 / .5$ & $4.7 / .5$ & 55 \\
\hline (C2) Reflection on experience (personal meaningfulness) & $4.7 / .5$ & $4.7 / .5$ & & 54 \\
\hline (T) The student's orientation to tasks and learning & $4.8 / .5$ & $4.7 / .6$ & $4.9 / .4$ & 54 \\
\hline (T1) Presenting a simple list of tasks performed & $3.4 / 1.1$ & $3.4 / 1.1$ & $2.7 / 1$ & 56 \\
\hline (T2) Presenting evidence of task prioritization & $4.7 / .7$ & $4.7 / .6$ & $4.7 / .8$ & 58 \\
\hline (T3) Comfort with nursing topics and terms & $4.6 / .7$ & $4.6 / .7$ & $4.7 / .5$ & 56 \\
\hline (T4) Information connected between classroom/clinical experience & $4.7 / .6$ & $4.7 / .6$ & $4.5 / .8$ & 53 \\
\hline (T5) Evidence of critical thinking/thought & $4.8 / .5$ & $4.8 / .5$ & $5.0 / 0$ & 53 \\
\hline (T6) Expression of what was learned/discovered & $4.8 / .6$ & $4.8 / .7$ & $5.0 / 0$ & 54 \\
\hline (M) The student's manner of speaking & $4.3 / .7$ & $4.3 / .7$ & $3.9 / .7$ & 60 \\
\hline (M1) Professional manner of speaking & $4.5 / .7$ & $4.6 / .6$ & $3.9 / .7$ & 59 \\
\hline (M2) Informal tone in speaking & $3.5 / 1$ & $3.5 / 1$ & $3.4 / 1$ & 59 \\
\hline (M3) Organized manner of presentation & $4.7 / .7$ & $4.7 / .7$ & $4.9 / .4$ & 59 \\
\hline (R) The recording quality and the tone of the student's voice & $3.7 / 1$ & $3.8 / 1$ & $3.1 / .7$ & 60 \\
\hline (R1)Enthusiastic tone & $4.3 / .8$ & $4.3 / .8$ & $4.1 / .9$ & 58 \\
\hline (R2) Bored or frustrated tone & $4.2 / 1.2$ & $4.2 / 1.2$ & $4.0 / 1.4$ & 57 \\
\hline (R3) Superficial or distracted tone & $4.2 / 1.2$ & $4.2 / 1.2$ & $4.0 / .5$ & 56 \\
\hline (R4) Presence of background sounds/voices & $3.4 / 1.2$ & $3.5 / 1.2$ & $2.7 / .5$ & 58 \\
\hline
\end{tabular}

Perceptions of the communicative elements are subjective, and lacking a specifically designed rubric these elements may not be able to be assessed appropriately. Creating a rubric though, cannot include everything an instructor utilizes when grading (Osborne and Walker, 2013). Survey comments however show that these elements appear to shape the instructors' perceptions of a student's learning and development. Elements that are not necessarily unique to voice reflections, such as connecting the classroom and clinical experience, evidence of critical thinking, indications of personal reflection, and expressions of care and empathy for the patient were indicated as being perceivable in the survey. The respondents easily perceived and often had a consensus agreement on the presence of or lack of presence of the voice reflection factors provided. Also they overwhelmingly felt these unique factors to be important in their hypothesized assessment process. Therefore these unique factors can be considered valid elements that may play into an instructor's assessment. The instructors who responded to this survey found the ability of students to record a reflection interesting, viable, and possibly worth trying in a course of their own.

This study represents a small early step in the process of integrating digital voice recording as part of a pedagogical strategy. It builds upon a commonly used tool, reflection, but adapts that tool to the technical capacities and time demands of the present day. Text dissemination of reflective knowledge can be scored based on the objective and subjective assessment of a student's writing skills, which are skills that lay outside of the realm of reflection, the true purpose of the assigned task. The score does not truly mirror whether the reflec- tion was meaningful or transformative if the writing skill of the student is a strongly considered part of the assessment. The subtle emotional nuance of discovery or personal revelation becomes subject to the ability of the student to write well, and subsequently it may not translate to text in a manner that can be readily or meaningfully perceived by an instructor looking for deeper learning.

Limited vocabulary skills may also hinder accurate representation of their expression and reflective emotional overtones. The instructor reading the reflection has no choice but to examine, take into account, and possibly be biased by the writing and vocabulary skills of the student, as it is the only representation of their experience. These are prerequisite factors that may overshadow the meaning of what the student was actually trying to relate.

As computer technology becomes smaller, more powerful, and portable, educators will likely rely more heavily on multimedia for communication and dissemination of learning from students, and students rely on technology for gathering information and communication (Bennett, Maton, \& Kervin, 2008). If this is the case, it is important to learn how instructors might consider a technical modality such as digital voice reflections as a useful means of learning. Though voice reflections also will be assessed both objectively and subjectively, they will offer different assessment challenges to an instructor. The student may follow the recipe-like prompting rubric, but their vocal quality and skills such as vocabulary, manner of speaking, and tone of voice will come into the assessment process much as their 
writing skills currently do. Voice reflections will provide additional rich material such as vocally inflected emotional cues from which the instructor can gauge learning and a student's attitude. It is important then to know what instructors perceive, and how important those perceptions are to their assessment, which was the aim of this study.

In summary, reflection is an important part of education. Recording reflective assignments gives an instructor the opportunity to review the student's spoken word, such as their manner of speaking and voice inflection, and assess their learning, personal relationship and experiential transformation. Though instructor perceptions of manner of speech and inflection are largely subjective in nature, these unique factors by virtue of their mere presence can be an element in shaping an instructor's assessment. Personal and professional transformation in education involves reflection, and technologies such as digital voice reflection can assist an instructor's assessment by providing not only evidence of learning but also some insight into the student's personal and professional view of the experience and their transformation.

\section{References}

Asselin, M. E., Schwartz-Barcott, D. Osterman, P. A. (2012). Exploring reflection as a process embedded in experienced nurses' practice: A qualitative study. Journal of Advanced Nursing, 69(4), 905-914.

Bennett, S., Maton, K., \& Kervin, L. (2008). The 'digital natives' debate: A critical review of the evidence. British Journal of Educational Technology, 39(5), 775-786.

Boud, D., Keogh, R., \& Walker, D. (1985). Reflection: Turning experience into learning. London: Kogan Page.

Dewey, J. (2001). How We Think. New York: Digiread.com Publishing (http:// www.digireads.com). (Original work published 1910)

Dahlstrom, E., Walker, J. D., \& Dzuiban, C., (2013). ECAR study of undergraduate students and information technology, 2013 (research report). Retrieved October, 15, 2015 from [Louisville, CO: EDUCAUSE Center for Analysis and Research, www.educause.edu/ecar]

Fraenkel, J. R., \& Wallen, N. E. (2009). How to design and evaluate research in education. New York, NY: McGraw-Hill Higher Education.

Hannigan, B. (2001). A discussion of the strengths and weaknesses of 'reflection' in nursing practice and education. Journal of Clinical Nursing, 10(2), 278283.

Hatton, N., \& Smith, D. (1995). Reflection in teacher education: Towards definition and implementation. Teaching \& Teacher Education, 11, 33-49.

Kember, D., McKay, J., Sinclair, K., \& Wong, F. K. Y. (2008). A four-category scheme for coding and assessing the level of reflection in written work. As- sessment and Evaluation in Higher Education, 33(4), 369-379.

Mann, K., Jordon, J., \& MacLeod, A. (2009). Reflection and reflective practice in health professions education: A systematic review. Advances in Health Sciences Education: Theory and Practice, 14(4), 595 $-621$.

Mezirow, J. (1981). A critical theory of adult learning and education. Adult Education, 1(32), 3- 24.

Mezirow, J. (1991). Transformative dimensions of adult learning. San Francisco: Jossey-Bass. Mezirow, J. (1997). Transformative learning: Theory to practice. New Directions for Adult \&Continuing Education, (74), 5.

Moon, J. (1999). A handbook of reflective and experiential learning. London: Routledge. Moon, J. (2004). A handbook of reflective and experiential learning: Theory and Practice.London: Routledge Farmer.

Osborne, J., \& Walker, P. (2014). Just ask teachers: Building expertise, trusting subjectivity, and valuing difference in writing assessment. Assessing Writing, $22,33-47$.

Pierson, W. (1998). Reflection and nursing education. Journal of Advanced Nursing, 27(1), 165- 170.

Schön, D. (1991). The Reflective Practitioner (2nd ed.). San Francisco: Jossey Bass.

Smith, E. (2011). Teaching critical reflection. Teaching in Higher Education, 16(2), 211-223. 